\title{
Taxonomic study of some species of the subfamily Dipsacoideae Eaton (Caprifoliaceae) by phenolic acid profiles
}

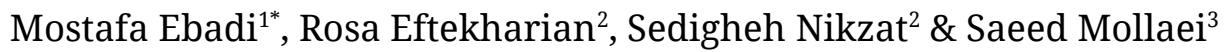 \\ ${ }^{1}$ Department of Biology, Faculty of Sciences, Azarbaijan Shahid Madani University, Tabriz 53714-161, Iran \\ ${ }^{2}$ Faculty of Life Sciences \& Biotechnology, Shahid Beheshti University, Tehran, Iran \\ ${ }^{3}$ Department of Chemistry, Faculty of Sciences, Azarbaijan Shahid Madani University, 53714-161, Tabriz, Iran \\ *Email: ebadi2023@yahoo.com
}

\section{ARTICLE HISTORY}

Received: 23 May 2021

Accepted: 26 August 2021

Available online: 27 September 2021

\section{KEYWORDS}

Chemotaxonomy

Diversity

PCA

PCOA

\section{ABSTRACT}

Dipsacoideae has always been problematic for taxonomic delimitation of the taxa because of their morphological similarities and diversity amongst the taxa. Phenolic compounds are found in various organs of plants and are important in terms of chemotaxonomy and pharmacognosy. In this study, the phenolic acid compounds of 12 species of Dipsacoideae were analyzed using high-performance liquid chromatography photodiode array detection (HPLC-PDA) and also evaluated their significances as chemotaxonomic markers. The main phenolic acids were found to be caffeic acid, p-coumaric acid, ferulic acid and salicylic acid. The principal components analysis (PCA) bi-plot indicated that ferulic acid, caffeic acid, cinnamic acid, p-coumaric acid and rosmaric acid were principal components in the studied species dispersion. The species were separated from each other in a principal coordinate analysis (PCOA) plot in terms of their phenolic acid profile. Regarding the results, the high amount of caffeic acid and cinnamic acid could be considered a chemotaxonomic marker for genus Pterocephalus Vaill. and Cephalaria Schrad. respectively. The results indicated that Scabiosa koelzii Rech. and S. amoena Jacq. were placed as a distinct group regarding their phenolic acid profile and established the opinion supported by Greuter and Raus. Consequently, phenolic contents could be applied as a significant marker in the chemotaxonomy of Dipsacoideae. Considering it, we suggest the study of interaction among ecological and genetically factors as well as the studied chemical compounds.

\section{Introduction}

Dipsacoideae Eaton (APG III; Caprifoliaceae, Dipsacales) contains ca. 150 species of perennial or biennial herbs and shrubs classified in 14 genera distributed in Europe, Asia and Africa (1). Some species are ornamental, noxious weeds and identified as herbal medicine sources $(2,3)$. Dipsacoideae has always been discussed for delimitation of the taxa, concerning morphological similarities and high diversity amongst the taxa, especially calyx and fruit characters in genera Scabiosa L. and Pterocephalus Vaill. (4). Therefore, the taxonomy and phylogenetic of taxa within the Dipsacoideae subfamily have been significantly changed over time.

First, Linnaeus distinguished three genera that include Scabiosa L., Dipsacus L. and Knautia L. The genera Pterocephalus Vaill, Succisa Haller, Cephalaria Schrad. ex Roem \& Schult. were later segregated from Scabiosa L. (5).
Dipsacoideae was divided into two tribes by De Candolle, viz. Morineae (including genus Morina L.) and Scabioseae (including Dipsacus L., Cephalaria Schrad., Pterocephalus Vaill., Knautia L. and Scabiosa L.) (6). In addition, Verlaque divided this sub-family into three tribes with nine genera (4). Major revisions to Scabioseae divided Scabiosa sensu lato into 6 genera: Lomelosia Raf., Scabiosa sensu stricto, Pseudoscabiosa Dev., Pterocephalidium (Lag.) G. Lopez, Pycnocomon Hoffmanns. and Link and Sixalix Raf. (7, 8).

Phylogeny has widespread advantages in interdisciplinary studies including taxonomy, evolutionary biology, biogeography, ecology, conservation and even medicine $(9,10)$. Relatively little phylogenetic work has focused on Dipsacoideae. Caputo and Cozzolino (11) used morphology traits for the first phylogenetic study of Dipsacoideae, widely supported the traditional definitions described above. On the contrary, molecular phylogenetic results were

C Ebadi et al (2021). This is an open-access article distributed under the terms of the Creative Commons Attribution License, which permits unrestricted use, distribution and reproduction in any medium, provided the original author and source are credited (https://creativecommons.org/licenses/by/4.0/). 
in contrast to the previous morphological works and supported the revisions to tribes and genera (12). In this way, two major clades in Dipsacoideae were identified: Scabioseae sensu stricto and a clade containing Dipsaceae, Knautieae and the groups excluded from Scabioseae sensu lato [Pseudoscabiosa Dev., Pterocephalidium (Lag.) G. Lopez, Succisa Haller, Succisella Beck] (11). As a result, taxonomic evidence of this sub-family can be very effective in classifying the status rank of taxa within different genera and species.

Most of the recent chemotaxonomic knowledge was applied in order to study the phylogenetic relationships of plants (13). Secondary metabolites, in particular phenolic compounds, are extensively used in chemotaxonomy investigations in terms of their widespread dissemination in vascular plants, structural variation and chemical stability (14-19). The phenolic compounds value has been proven to be the appropriate taxonomic marker in different taxonomic ranks (13). In Dipsacoideae, the fatty acid and sterol composition of eight taxa belonging to three genera Scabiosa, Cephalaria and Pterocephalus were investigated (20). Moreover, reports are on studied chemotaxonomic status and fatty acid compositions of eleven species of Scabiosa (21).

This study aimed to investigate the phenolic acid compounds diversity in the aerial parts of 12 species of Dipsacoideae from Iran, using HPLC method and their significance evaluation as chemical markers for taxonomic purposes.

\section{Materials and Methods}

\section{Plant material}

In this study, 12 species (one accession per species) belonged to 4 Dipsacoideae genera were collected from seven provinces of Iran during spring and summer in 2015-2017. The species identification was performed using literature $(22,23)$. The list of voucher specimens and localities were presented in Table 1.

\section{Extraction of free phenolic acids}

Free phenolic acids were extracted using the method described (24). In this method, $5 \mathrm{ml}$ of $80 \%$ ethanol were added to $0.5 \mathrm{~g}$ of dried powdered sample (aerial parts of plant) and they were mixed at $3000 \mathrm{rpm}$ on a vortex mixer for $5 \mathrm{~min}$. The mixture was centrifuged (Rotina 420R Hettich, German) at a speed of $6000 \times \mathrm{g}$ for $5 \mathrm{~min}$. The supernatant was decanted, evaporated and was stored in an amber glass vial $\left(-20^{\circ} \mathrm{C}\right)$ for additional analysis.

\section{Analysis of phenolic acids}

The phenolic compounds analysis was accomplished using an HPLC (Waters 2695, USA) system equipped with a diode-array detector, a $20 \mu \mathrm{l}$ loop and a C18 analytical column $(250 \times 0.46 \mathrm{~mm}, 5 \mu \mathrm{m})$. Separation was performed by the use of a gradient programme run at room temperature, which consist two solvents: solvent A $(0.1 \%$ TFA in methanol) and solvent B (0.1\% TFA in water, v/v) as following: $20 \%$ $\mathrm{A}$, at $0 \mathrm{~min} ; 30 \% \mathrm{~A}$, (from 0 to $10 \mathrm{~min}$ ); $60 \% \mathrm{~A}$, (from 10 to $30 \mathrm{~min}$ ); $80 \% \mathrm{~A}$, (30 to $40 \mathrm{~min}$ ); $100 \% \mathrm{~A}$, (40 to $45 \mathrm{~min}$ ); $20 \% \mathrm{~A}$, (from 45 to $52 \mathrm{~min}$ ); isocratic, $6 \mathrm{~min}$. The flow rate of the mobile phase was maintained at $1 \mathrm{ml} / \mathrm{min}$, and the wavelength was adjusted at 254, 275 and $320 \mathrm{~nm}$. The identification of studied phenolic acids was evaluated by retention times and the analysis of spiked crude extract with standards solution. For the quantitative analysis of phenolic acid compounds, calibration curves were obtained via the injection of different concentrations of standard compounds (5, 20, 40, 60, 80 and $100 \mathrm{ppm}$ ). The results were expressed as micrograms per $\mathrm{g}$ of dry weight extract. Experiments were performed in triplicate repeats.

\section{Statistical analysis}

The most variable phenolic acids were identified by Principal Components Analysis (PCA biplot) in order to avoid from the misclassification of the taxa. Box plots of significance phenolic acids were applied to display the means and variable characters range amongst different taxa. Principal Coordinate Analysis (PCoA) was performed for the variable phenolic acid content of investigated taxa with Euclidean as similarity index. Statistical analysis was accomplished using the PAST ver. $2.17 \mathrm{c}$ programme.

\section{Results}

This study was the first study that quantifies phenolic acid compounds of 12 species of Dipsacoideae in Iran. In general, 11 phenolic acid compounds were evaluated in methanol extracts of studied species using the HPLC-PDA (Fig. 1). Totally, 10, 9, 8, 7, 9, 8, 8, 9, 9, 9, 8 and 8 phenolic acid compounds were identified in D. pilosus, C. procera, P. plumosus, $C$.

Table 1. Name, place of collection and vouchers of studied taxa of Dipsacoideae sub-family.

\begin{tabular}{llll}
\hline Genus & Species & Locality & Voucher No. \\
\hline Cephalaria Schrad. & C. kotschyi Boiss. & Mazndaran, Chalus & ASMUH95001 \\
\hline & C. procera Fisch. & Ardebil, Khalkhal & ASMUH95002 \\
\hline C. syriaca (L.) Schrad. & Tehran, Darakeh & ASMUH95010 \\
\hline Dipsacus L. & D. pilosus L. & Tehran, Darakeh & ASMUH95011 \\
\hline Pterocephalus Vaill. & D. strigosus Willd. & Mazndaran, Chalus & ASMUH95005 \\
\hline & P. canus Coul. & Tehran, Ab-ali & ASMUH95004 \\
\hline Scabiosa L. & P. plumosus (L.) Coult. & Mazndaran, Chalus & ASMUH95003 \\
\hline & S. caucasica M. B. & Ardebil & ASMUH95006 \\
\hline S. amoena Jacq. & Masuleh & ASMUH95007 \\
\hline S. ooelzii Rech. f. & Bojnord & ASMUH95008 \\
\hline & S. rotata Bieb. & Mashhad & ASMUH95009 \\
\hline
\end{tabular}




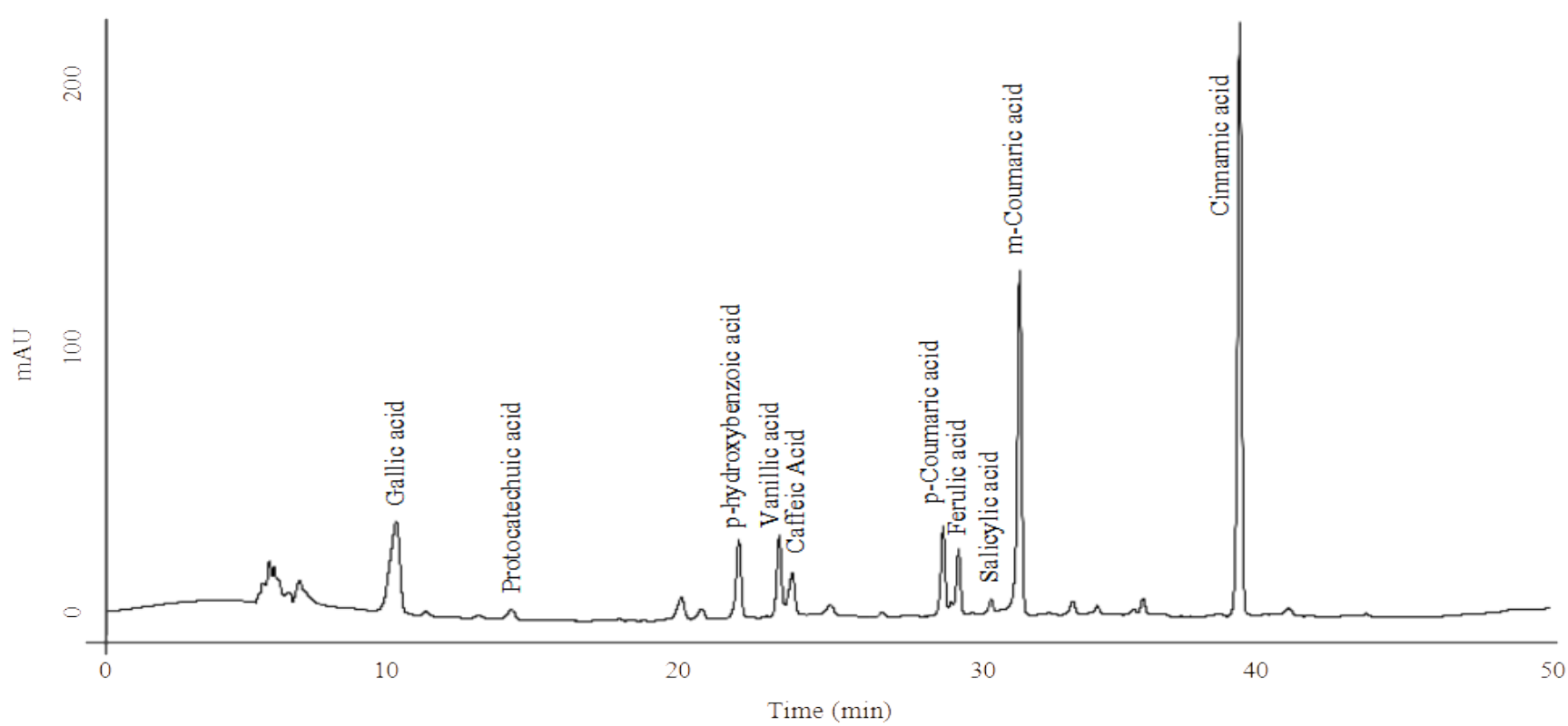

Fig. 1. HPLC chromatogram of phenolic acid extract from Dipsacus pilosus L.

syriaca, $S$. persica, D. strigosus, $C$. kotschyi, $S$. rotata, $S$. amoena, $S$. koelzii, $S$. caucasica and $P$. canus with the total amount of $5.752,10.207,11.383,11.317,6.719$, 5.702, 12.388, 8.274, 6.077, 6.087, 6.597 and $6.853 \mathrm{mg} / \mathrm{g}$ dried weight respectively (Table 2). The dominant components included caffeic acid, p-coumaric acid, ferulic acid and salicylic acid (Table 3). Gallic acid, caffeic acid, p-coumaric acid, m-coumaric acid and salicylic acid were present in all taxa, and their
$3.145 \pm 0.100 \mathrm{mg} / \mathrm{g}$ dried weight respectively. Ferulic acid was not observed in $P$. canus, whereas the highest amounts were associated with $C$. kotschyi, S. amoena and $S$. koelzii with values of $1.452 \pm 0.100,1.259 \pm 0.010$ and $1.087 \pm 0.069 \mathrm{mg} / \mathrm{g}$ dried weight respectively. pHydroxybenzoic acid was another phenolic acid compound in all the investigated species, except $P$. plumosus and $P$. canus.

Table 2. Amount of phenolic acid compounds (mg/g dried weight; mean \pm S.E.) in some species of Dipsacoideae sub-family.

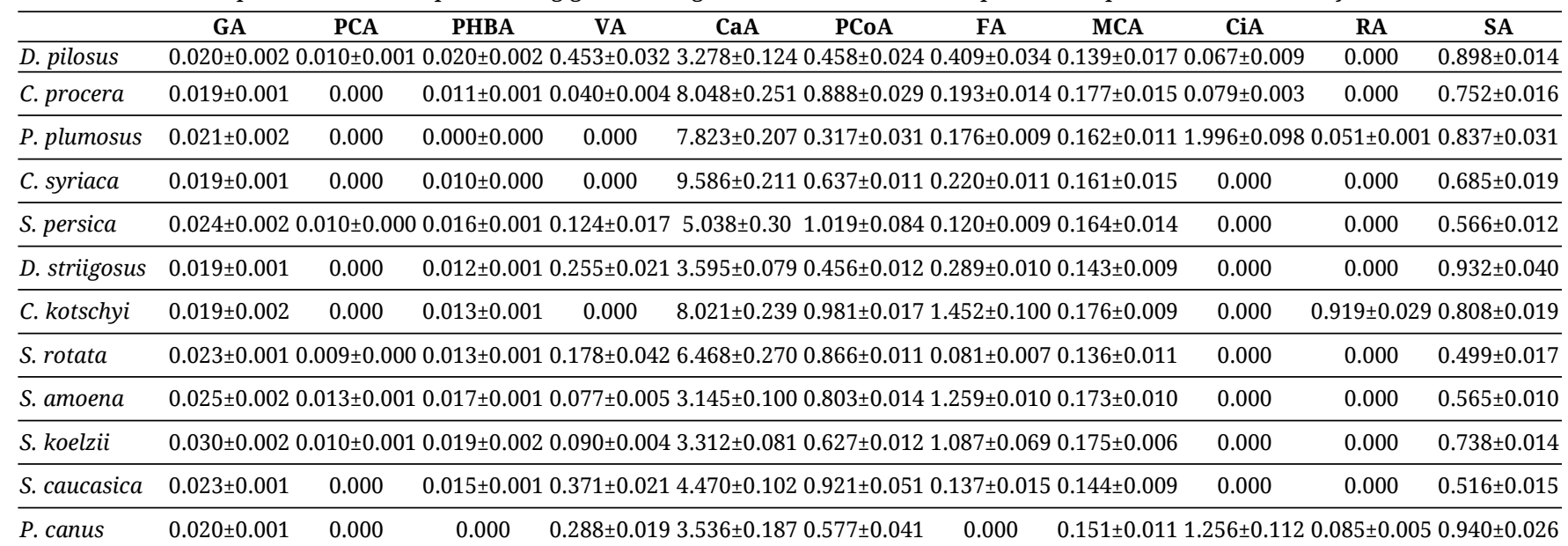

GA: Gallic acid; PCA: Protocatechuic acid; PHBA: p-Hydroxybenzoic acid; VA: Vanillic acid; CaA: Caffeic acid; PCoA: p-Coumaric acid; FA: Ferulic acid; MCA: m-Coumaric acid; CiA: Cinnamic acid; RA: Rosmaric acid; SA: Salicylic acid

highest amount was related to $S$. koelzii, $C$. syriaca, $S$. persica, $C$. procera and $P$. canus with values of $0.030 \pm 0.002,9.586 \pm 0.211,1.019 \pm 0.084,0.177 \pm 0.015$ and $0.940 \pm 0.026 \mathrm{mg} / \mathrm{g}$ dried weight respectively. The highest amounts of protocatechuic acid, cinnamic acid and rosmaric acid were related to $S$. amoena, $P$. plumosus and $C$. kotschyi with values of $0.013 \pm 0.001$, $1.996 \pm 0.098$ and $0.919 \pm 0.029 \mathrm{mg} / \mathrm{g}$ dried weight respectively. Moreover, the highest and lowest caffeic acid amounts were associated with $C$. syriaca and $S$. amoena with the following values $9.586 \pm 0.211$ and
The PCA bi-plot of the 11 distinct phenolic acids demonstrated that the ferulic acid, caffeic acid, rosmaric acid, cinnamic acid and p-coumaric acid were principal components in the studied taxa dispersion (Fig. 2). For example, the highest and lowest amount of ferulic acid was in $C$. kotschyi $(1.452 \pm 0.100 \mathrm{mg} / \mathrm{g}$ dried weight) and $S$. rotata $(0.081 \pm 0.007 \mathrm{mg} / \mathrm{g}$ dried weight) respectively. The caffeic acid amount varied between $3.145 \pm 0.100 \mathrm{mg} / \mathrm{g}$ dried plant in S. amoena to $9.586 \pm 0.211 \mathrm{mg} / \mathrm{g}$ dried weight in $C$. syriaca. 
Table 3. Eigen-values, estimated and cumulative variance for seven factors obtained from principal components.

\begin{tabular}{|c|c|c|c|c|c|c|c|}
\hline \multirow{2}{*}{ Compounds } & \multicolumn{7}{|c|}{ Principal components } \\
\hline & 1 & 2 & 3 & 4 & 5 & 6 & 7 \\
\hline Caffeic acid & 18.02 & -0.06 & -0.07 & $\begin{array}{l}-0.12 \\
\end{array}$ & $\begin{array}{l}-0.02 \\
\end{array}$ & -0.02 & 0.01 \\
\hline p-Coumaric acid & -0.31 & 0.62 & -0.29 & 0.45 & 0.51 & 0.09 & -0.04 \\
\hline Ferulic acid & -1.27 & 1.18 & 1.09 & -0.06 & 0.01 & -0.15 & 0.04 \\
\hline Cinnamic acid & -1.65 & -1.93 & 0.59 & 0.03 & 0.17 & -0.01 & 0.02 \\
\hline Rosmaric acid & -2.26 & 0.24 & 0.08 & -0.62 & -0.03 & 0.44 & -0.01 \\
\hline Gallic acid & -2.57 & -0.02 & -0.31 & -0.21 & -0.04 & -0.14 & -0.03 \\
\hline p-Hydroxybenzoic acid & -2.61 & -0.01 & -0.32 & -0.22 & -0.05 & -0.14 & -0.03 \\
\hline Protocatechuic acid & -2.63 & -0.02 & -0.31 & -0.23 & -0.05 & -0.14 & -0.03 \\
\hline m-Coumaric acid & -2.13 & 0.03 & -0.23 & -0.07 & -0.02 & -0.13 & -0.04 \\
\hline Vanillic acid & -2.27 & 0.01 & -0.40 & 0.32 & -0.12 & 0.06 & 0.21 \\
\hline Salicylic acid & -0.33 & -0.03 & 0.17 & 0.73 & -0.34 & 0.14 & -0.10 \\
\hline Eigen-value & 36.44 & 0.56 & 0.22 & 0.14 & 0.04 & 0.03 & 0.01 \\
\hline Variance (\%) & 97.35 & 1.49 & 0.58 & 0.37 & 0.12 & 0.08 & 0.01 \\
\hline Cumulative variance & 97.35 & 98.84 & 99.42 & 99.79 & 99.91 & 99.99 & 100 \\
\hline
\end{tabular}

The main PC (component 1) explained $97.40 \%$ of the variation and had a positive correlation with caffeic acid. Also, PC2 (component 2) had a positive correlation with ferulic acid, p- coumaric acid and rosmaric acid.

Box-Plot graphs were applied for highlighting the phenolic acid compounds distributions amongst those investigated taxa. Box plots indicated that some quantitative phenolic acid compounds were more addition, D. pilosus and D. strigosus were placed close to each other and the species of Scabiosa were placed in another group.

\section{Discussion}

Phenolic acid compounds are considered an important class of secondary metabolites in Dipsacoideae. As phenolic compounds have high

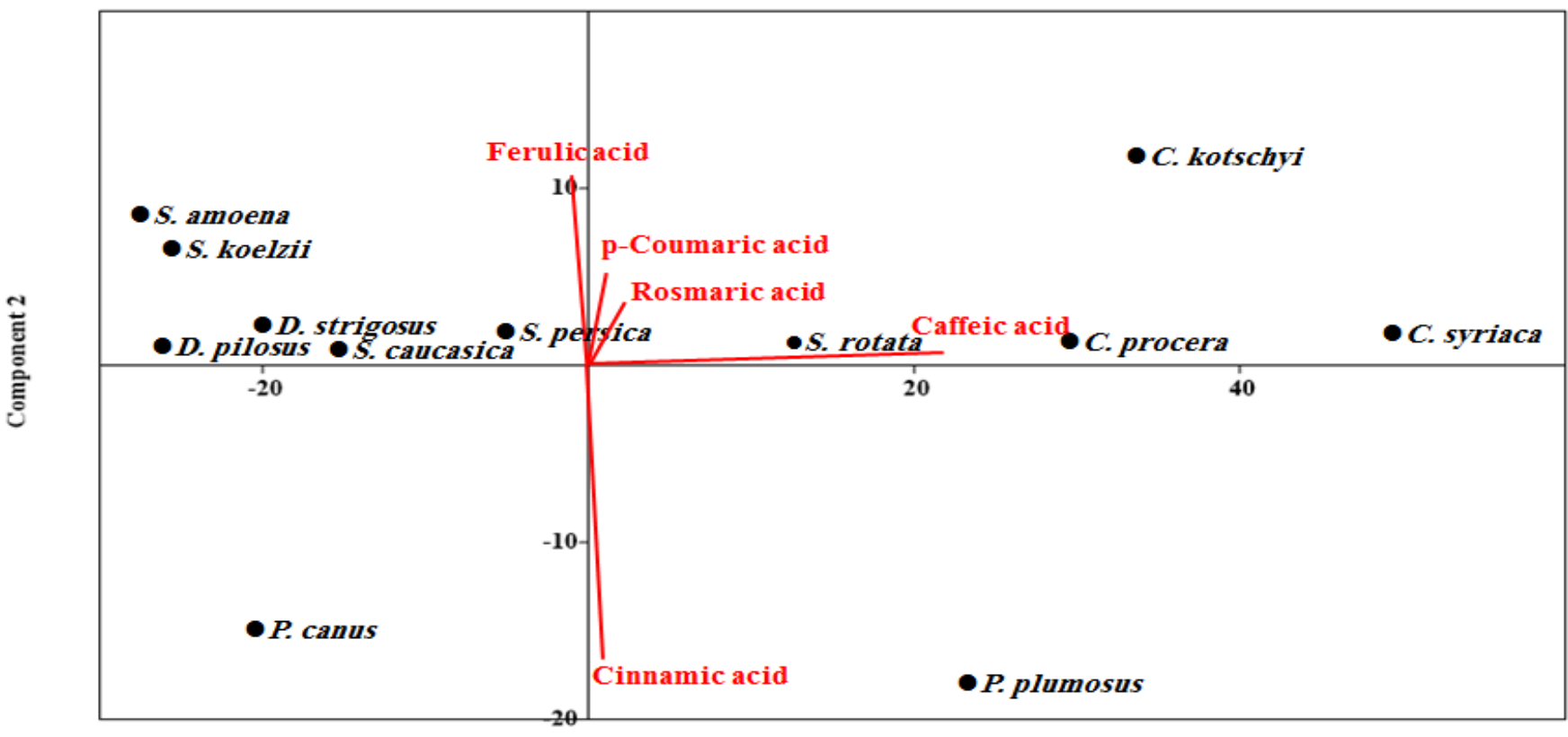

Component 1

Fig. 2. Principal Component Analysis (PCA) among studied species based on phenolic acid compounds.

valuable in the taxa identification (Fig. 3). For example, cinnamic acid quantity was a useful character in $P$. canus and $P$. plumosus identification from other taxa. A high amount of rosmaric acid can be used for recognizing $C$. kotschyi.

PCoA analysis revealed each studied species distribution due to phenolic acid contents (Fig. 4). Due to high amount of caffeic acid ( $>8 \mathrm{mg} / \mathrm{g}$ dried weight), Cephalaria were categorized into separate groups. In evolutionary rates compared to molecular markers like DNA sequences, they are important in phylogenetic studies and have been used at lower taxonomic ranks (25). The evolution within the Dipsacoideae followed complex paths and several genera were polyphyletic $(25,26)$. This sub-family has always been subjected to the argument for the taxa delimitation. de Castro and Caputo indicated that there is a high degree of homoplasy at the generic level in Dipsacoideae (27). This research indicated the 


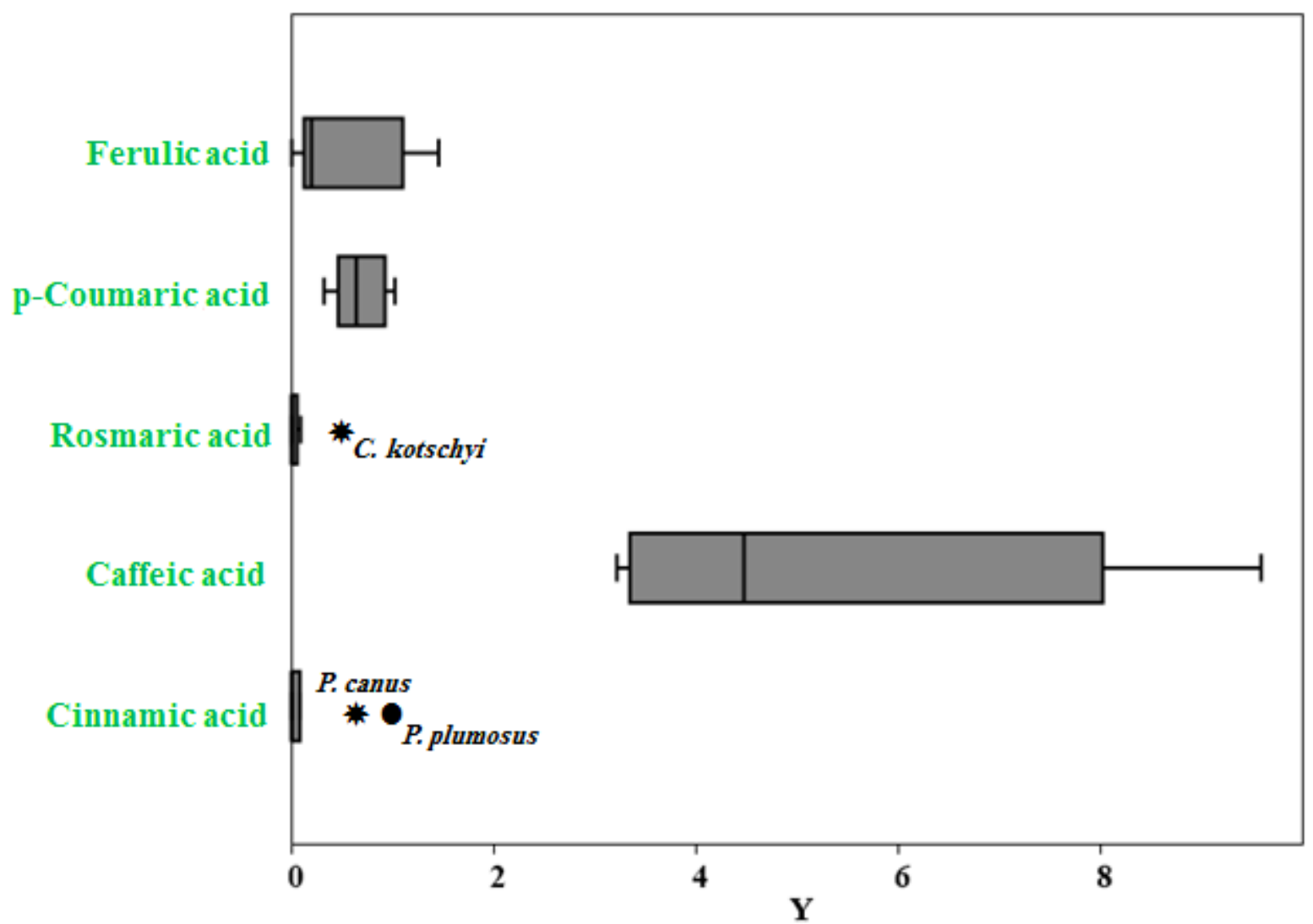

Fig. 3. Box plot of the most variable phenolic acid content among studied species of Dipsacoideae sub-family.

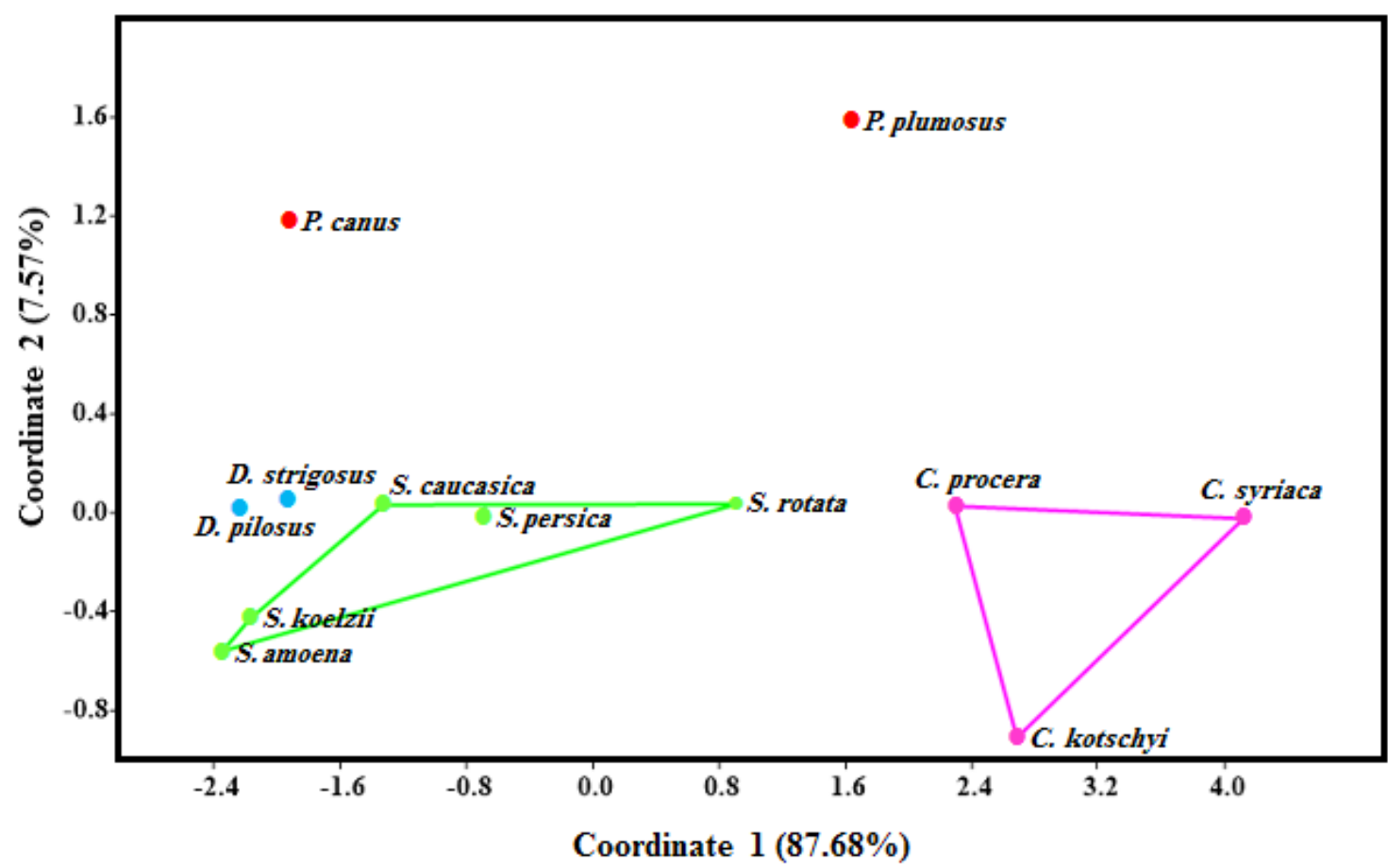

Fig. 4. Two-dimensional plot of Principal Coordinate Analysis (PCOA) of studied species based on phenolic acid compounds.

high variation of phenolic acid content amongst the Dipsacoideae. In this study, the PCoA plot showed that there are significant differences amongst the various species and genera, with respect to phenolic acid compounds.
Given to the taxonomical aspect, the Scabiosa is the most important genus of the Dipsacoideae due to ambiguous in the number of reported species $(28,29)$. It was reported that there are 22 species of Scabiosa L. in the Flora Iranica, which belonged to three sections: 
Scabiosa, Asterocephalus and Olivierianae (23). Greuter and Raus categorized Iranian species of Scabiosa into two genera as Lomelosia Raf. (= Scabiosa sect. Astrocephalus Coult. and sect. Olivierinae Coult.) and Scabiosa s. str. (=Scabiosa sect. scaboisa L.) (30). On the basis of the plant list, situation of $S$. koelzii and $S$. amoena is unresolved. However, based on one study, involucel tubes of Lomelosia had eight apical pits, whereas Scabiosa included eight longitudinal grooves (30). Therefore, among the studied species, S. koelzii and $S$. amoena could be remaining as species of the genus Scabiosa and three other species could be transferred to Lomelosia. Given to character of pitted epicalyx, the relocation of four species from Scabiosa to Lomelosia was reported (31).

According to our earlier reports, S. koelzii and $S$. amoena were placed as a distinct group from other Scabiosa species due to their fatty acid profile and palynological characters and confirmed the opinion supported $(21,32)$. The taxonomic differentiation between two sections (Scabiosa and Asterocephalus) was followed by variation in their phenolic acid compounds. In conclusion, in this study, the phenolic acid results established the opinion supported by a previous study, that Scabiosa sect. Asterocephalus was well transferred taxonomically to Lomelosia (30).

In recent studies, phytochemical studies of Cephalaria species indicated salicylic acid, p-coumaric acid, vanillic acid, gallic acid and caffeic acid presence (33, 34), consistent with this study results. In the PCoA plot, species of Cephalaria were located in a group because their phenolic acid compositions were similar. This means that these compounds, especially the high content of caffeic acid, can be considered useful to recognize the Cephalaria spp. It was reported that caffeic acid was the main phenolic acid in n-butanol extract of $C$. davisiana (34). In addition, $C$. kotschyi was separated from $C$. syriaca and $C$. procera based on the presence of ferulic acid and rosmaric acid.

The high amount of cinnamic acid was distinguished at $P$. plumosus and $P$. canus. This compound has been identified as an interesting compound with anti-inflammatory, antioxidant and cytotoxic properties. Although $P$. plumosus and $P$. canus were placed apart from each other with respect to the PCoA plot, the cinnamic acid content of these two taxa was high and could be considered as a biomarker for this genus.

The extract of $D$. asperoides has been reported to have various phenolic acids compounds such as pcoumaric acid, o-coumaric acid, ferulic acid, caffeic acid and vanillic acid, which is in agreement with our results (35). Moreover, the caffeic acid, cinnamic acid derivate and vanillic acid were identified in $D$. asper and $D$. fullonum $(36,37)$. In addition, salicylic acid for the first time was identified at $D$. pilosus and $D$. strigosus in our study.

\section{Conclusion}

The investigated taxa of Dipsacoideae were recognized using the phenolic acid profile and these compounds could be applied in the Dipsacoideae chemotaxonomy as a significance marker. Regarding future phylogenetic studies in this subfamily, it is highly recommended to investigate the interaction of molecular marker and chemotaxonomy, as well as environmental factors.

\section{Acknowledgements}

We gratefully acknowledge financial support from Azarbaijan Shahid Madani University.

\section{Authors' contributions}

All authors contributed equally.

\section{Compliance with ethical standards}

Conflict of interests: The authors declare that there exists no conflict of interest.

\section{References}

1. Reveal JL, Chase MW. APG III: bibliographical information and synonymy of Magnoliidae. Phytotaxa. 2011;19:71-34.

2. Rector BG, Harizanova V, Sforza R, Widmer T, Wiedenmann RN. Prospects for biological control of teasels, Dipsacus spp., a new target in the United States. Biol Control. 2006;36(1):1-14. https://doi.org/10.1016/j.biocontrol.2005.09.010

3. Bonet MA, Valle, sacute J. Ethnobotany of Montseny biosphere reserve (Catalonia, Iberian Peninsula): plants used in veterinary medicine. J Ethnopharmacol. 2007;110:130-47. https://doi.org/10.1016/j.jep.2006.09.016

4. Verlaque R. A biosystematic and phylogenetic study of the Dipsacaceae. In: Grant, R. (Ed.), Plant Biosystematics. Toronto. 1984. p.307-20.

5. Devesa JA. Revisidn del genero Scabiosa en la Peninsula Ibrrica e Islas Baleares. Lagascalia. 1984;12:143-12.

6. De Candolle AP. Prodromus Systematis Naturalis Regni Vegetabilis 4. Paris, France: Treuttel and Wurtz (in Latin); 1830.

7. Greuter W, Burdet HM. Dipsacaceae. Pp. 71-77. In: Greuter W, Raus T (eds), Med-Checklist Notulae 11. Willdenowia. 1985;15:61-48.

8. López González G. Pterocephalidium, un nuevo género ibérico de la familia Dipsacaceae. An Jard Bot Madr. 1987;43:245-52.

9. Hu H, Liu B, Liang Y, Ye J, Saqib S, Meng Z, Lu LM, Chen Z. An updated Chinese vascular plant tree of life: Phylogenetic diversity hotspots revisited. J Syst Evol. 2020;58(5):663-72. https://doi.org/10.1111/jse.12642

10. Zaman W, Saqib S, Ullah F, Ayaz A, Ye J. COVID-19: Phylogenetic approaches may help in finding resources for natural cure. $\begin{array}{lll}\text { Phytother } & \text { Res. 2020;34(11):2783-2785. }\end{array}$ https://doi.org/10.1002/ptr.6787

11. Caputo P, Cozzolino S. A cladistics analysis of Dipsacaceae (Dipsacales). Plant Syst Evol. 1994;189:41-61.

12. Caputo P, Cozzolino S, Moretti A. Molecular phylogenetics of Dipsacaceae reveals parallel trends in seed dispersal syndromes. Plant Syst Evol. 2004;246:163-75. https://doi.org/10.1007/s00606-004-0154-y

13. Noori M, ZareMayvan H, Mazaheri A. Leaf flavonoids of Chrozophora Neck (Euphorbiceae) members in Markazi province using chromatographical methods. J Med Plants. 2012;1(41 and S8):118-26 (in Persian).

14. Švehlíková V, Mráz P, Piacente S, Marhold K. Chemotaxonomic significance of flavonoids and phenolic acids in the Hieracium rohacsense group (Hieracium sect. Alpina; Lactuceae, Compositae). Biochem Syst Ecol. 2002;30(11):1037-49. https://doi.org/10.1016/S0305-1978(02)00056-X 
15. Nair VD, Panneerselvam R, Gopi R. Flavonoid as chemotaxonomic markers in endemic/endangered species of Rauvolfia from Southern Western Ghats of India: A preliminary study. Plant Biosyst. 2013;147:704-12. https://doi.org/10.1080/11263504.2012.727489

16. Mohyuddin A, Khan Z, Ahmad M, Kashmiri MA, Yasmin S, Mazhar H. Chemotaxonomic significance of flavonoids in the Solanum nigrum complex. J Chil Chem Soc. 2009;54(4): 486-90. http://dx.doi.org/10.4067/S0717-97072009000400037

17. Moubasher $\mathrm{H}$, AbdE-Ghani $\mathrm{M}$, Al-Wakeel S, Bahoor A Chemotaxonomic Significance of Flavonoids in Some Species of Galium (Rubiaceae) from Libya. Austin J Plant Biol. 2016;2(1):1014.

18. Lemma B, Grehl C, Zech M, Mekonnen B, Zech W, Nemomissa S, Bekele T, Glaser B. Phenolic compounds as unambiguous chemical markers for the identification of keystone plant species in the Bale mountains, Ethiopia. Plants. 2019;8:228. https://doi.org/10.3390/plants8070228

19. Ahmed A. Chemotaxonomic study based on flavonoid as taxonomic markers in the roots of the selected species belonged to family Solanaceae. Res J Plant Pathol. 2020;3(1):5. https://doi.org/10.4236/ajps.2019.1012160

20. Perdetzoglou DK, Kofinas C, Chinou I, Loukis A, Harvala C. A comparative chemotaxonomic study of eight taxa of the Dipsacaceae family. Plant Biosyst. 2000;134(2):213-18. https://doi.org/10.1080/11263500012331358494

21. Ebadi-Nahari M, Farnia P, Nikzat S, Mollaei S. A chemotaxonomic evaluation of some Scabiosa L. species in Iran $\begin{array}{llll}\text { Biochem } & \text { Syst } & \text { Ecol. } & \text { 2018;81:33-36. }\end{array}$ https://doi.org/10.1016/j.bse.2018.09.003

22. Jamzad Z. Flora of Iran, Vol. 8. Islamic Republic of Iran, Ministry of Jahad-e Sazandegi, Research Institute of Forests and Rangelands, Tehran. 1993; p. 1-106.

23. Rechinger KH, Lack HW. Dipsacaceae. In: Rechinger KH, (Ed), Flora Iranica. 1991;168:1-67. Verlag des Naturhistorischen Museums Wien

24. Hazrati S, Ebadi MT, Mollaei S, Khurizadeha S. Evaluation of volatile and phenolic compounds, and antioxidant activity of different parts of Ferulago angulata (Schlecht.) Boiss. Ind Crops Prod.

2019;140:111589. https://doi.org/10.1016/j.indcrop.2019.111589

25. Verlaque R. Rapports entre les Valerianaceae, les Morinaceaeet les Dipsacaceae. Bull Soc Bot. 1977;124:475-82. (in French).

26. Verlaque R. Etude biosystématiqueet phylogénétique des Dipsacaceae. Revue de cytologie et de biologie végétales; le botaniste. 1986;9:5-72. (in French).

27. De Castro OP. A phylogenetic analysis of genus Lomelosia Rafin (Dipsacaceae) and allied taxa. Delpinoa. 1999;41:29-45. https://doi.org/10.1007/s00606-009-0147-y

28. Bobrov EG. Dipsacaceae. In: In: Shishkin, RK. (Ed.), Flora of the USSR, vol. XXIV Akademii Nauk SSSR, Moscow. 1957.
29. Jasiewicz A. 1976. Scabiosa. In: Tutin TG (Ed), Flora Europaea, vol. 4. Cambridge University Press, Cambridge. 1957;p.68-74.

30. Greuter W, Raus T. Med-checklist Notulae 11. Willdenowia 15. Conservatoire et Jardin botaniques de la Ville de Geneve, Geneve. 1985;p.61-64.

31. Caputo P, Del Guacchio E. Transfer of four species of Scabiosa to Lomelosia (Dipsacaceae). Novon. 2011;21(4):402-04. https://doi.org/10.3417/2009135

32. Ebadi-Nahari M, Nikzat-Siahkolaee S, Eftekharian R. Pollen characters as taxonomic evidence in some species of Dipsacaceae from Iran. Bangladesh J Plant Taxon. 2017;42(2):129-36.

33. Ali KA, Sakri FQ, Li QX. Isolation and purification of allelochemicals from Cephalaria syriaca plant. Int J Biosci. 2012;2:90-03.

34. Sarikahya NB, Goren AC, Kirmizigul S. Simultaneous determination of several flavonoids and phenolic compounds in nineteen different Cephalaria species by HPLC-MS/MS. J Pharm Biomed Anal. 2019;173:120-25. https://doi.org/10.1016/j.jpba.2019.05.019

35. Li H, Zhang D, Tan LH, Yu B, Zhao SP, Cao WG. Comparison of the antioxidant properties of various solvent extracts from Dipsacus asperoides and identification of phenolic compounds by LC-ESI-QTOF-MS-MS. S Afr J Bot. 2017;109:1-8. https://doi.org/10.1016/j.sajb.2016.12.018

36. Tian XY, Wang YH, Liu HY, Yu SS, Fang WS. On the chemical constituents of Dipsacus asper. Chem Pharm Bull. 2007;55(12):1677-81. https://doi.org/10.1248/cpb.55.1677

37. Kuhtinskaja M, Vaher M. Extraction and analysis of bioactive compounds from Dipsacus fullonum and Galium verum for Lyme Borreliosis treatment. Biomed J Sci and Tech Res. 2018; 11(4):8614-16. https://doi.org/10.26717/BJSTR.2018.11.002121

\section{Additional information}

Peer review information: Plant Science Today thanks Sectional Editor and the other anonymous reviewers for their contribution to the peer review of this work.

Reprints and permissions information is available at https://horizonepublishing.com/journals/index.php/PST/open_access_policy

Publisher's Note: Horizon e-Publishing Group remains neutral with regard to jurisdictional claims in published maps and institutional affiliations.

To cite this article: Ebadi M, Eftekharian R, Nikzat S, Mollaei S. Taxonomic study of some species of the subfamily Dipsacoideae Eaton (Caprifoliaceae) by phenolic acid profiles. Plant Science Today. 2021;8(4):882-888. https://doi.org/10.14719/pst.2021.8.4.1270

Plant Science Today, published by Horizon e-Publishing Group, is covered by Scopus, Web of Science, BIOSIS Previews, Clarivate Analytics, etc. See https://horizonepublishing.com/journals/index.php/PST/indexing_abstracting 